\title{
PROGRAMAS DE INSERÇÃO À DOCÊNCIA: PERCEPÇÕES DE PROFESSORES UNIVERSITÁRIOS ${ }^{1}$
}

\author{
PROFESSORS' PERCEPTION OF \\ PROFESSIONAL INTEGRATION PROGRAMS
}

Neridiana Fabia Stivanin ${ }^{1}$, Beatriz Maria Boéssio Atrib Zanchet ${ }^{2}$

${ }^{1}$ Doutora em Educação pela Universidade Federal de Pelotas UFPel

${ }^{2}$ Professora titular da Universidade Federal de Pelotas - UFPel

\section{RESUMO}

Este estudo teve como objetivo investigar as percepções de professores universitários iniciantes sobre o programa de formação e inserção à docência desenvolvido em uma universidade do Rio Grande do Sul. Caracterizou-se pela abordagem qualitativa e teve como colaboradores 15 professores universitários, com até cinco anos de docência. Os dados foram coletados por meio de entrevistas e analisados à luz do referencial de Marcelo Garcia (1999, 2009), Mayor Ruiz (2007, 2009), dentre outros. É possível afirmar que programas dessa natureza, quando proporcionam discussões pedagógicas e ajudam na inserção dos professores, tornam-se possibilidades concretas de formação e qualificam o processo de desenvolvimento profissional.

Palavras-chave: Docentes universitários iniciantes. Formação docente. Programas de inserção profissional.

\footnotetext{
${ }^{1}$ Esta investigação é oriunda da tese de doutoramento de Neridiana Fabia Stivanin e contou com o financiamento da CAPES.
} 


\section{ASPECTOS INTRODUTÓRIOS: O INÍCIO DA CARREIRA DOCENTE}

Ao estudar o período de inserção na docência universitária de professores com formação em cursos de bacharelado e/ou profissionais liberais, é possível observar que esses professores ${ }^{2}$, quando ingressam na carreira, desempenham atividades de ensino para as quais não tiveram formação pedagógica. Iniciam os trabalhos em sala de aula, de maneira geral, sem conhecimentos pedagógicos que os ajudem a desenvolver o processo de ensino pelo qual são responsáveis. As práticas que adotam, na maioria das vezes, seguem os modelos de ex-professores, sem grandes questionamentos sobre questões pedagógicas que as envolvem.

É necessário considerar que, no Brasil, a Lei de Diretrizes e Bases da Educação (LDB), no 9.394/96, no artigo 66, trata a formação do docente como preparação de professores para atuar no ensino superior, prescrevendo que aquela "[...] far-se-á em nível de pós-graduação, prioritariamente em programas de mestrado e doutorado" - é sabido que esses programas são centrados no aprofundamento especializado em uma área do conhecimento. Poucos são os programas de pós-graduação que oferecem possibilidades de discussões e/ ou estudos de cunho didático-pedagógico.

\footnotetext{
${ }^{2}$ Tratamos aqui de professores que não possuem cursos de licenciatura, ou seja, são professores que assumiram a docência sem a formação pedagógica específica de cursos que formam professores.
} 
Em consequência dessa formação, como explicam Pimenta e Almeida (2009, p. 20-21), ao iniciarem a carreira universitária, os professores desconhecem cientificamente os elementos constitutivos da docência, como "planejamento, organização da aula, metodologias e estratégias didáticas, avaliação, peculiaridades da interação professor-aluno", conhecimentos esses indispensáveis para o desenvolvimento da docência.

As investigações sobre o início na profissão docente assinalam que a maioria dos professores ingressantes vive os primeiros anos de trabalho como uma experiência problemática e estressante. Precisam aprender a usar os recursos pessoais de que dispõem para enfrentar situações do ensino. Nesse começo de carreira, ocorre um processo de reorganização dos conhecimentos aprendidos enquanto eram estudantes para que possam, então, ensiná-los aos alunos, e isso não é tarefa fácil.

Autores como Marcelo Garcia (1999), Veeman (1988), Mayor Ruiz (2009), Huberman (1992), Feixas (2002), Bozu (2009, 2010), Isaia, Maciel e Bolzan (2010), Papi e Martins (2010), Sanchez Moreno e Mayor Ruiz (2006) nos ajudam a melhor compreender esse período desafiante. Esses autores vêm desenvolvendo investigações especificamente voltadas a entender o processo de inserção na docência. É possível observar, nessas pesquisas, diferentes formas com que se referem a esse período.

Burke, Fessler e Christensen (1984, apud MARCELO GARCIA, 1999, p. 114) fazem referência a um período de socialização que ocorre num jogo de relações entre o profissional e o sistema. Eles caracterizam esse momento como aquele 
"em que o professor principiante se esforça por aceitar os estudantes, os colegas e supervisores, e tenta alcançar um certo nível de segurança no modo como lida com os problemas e questões do dia a dia".

Ao pesquisar os professores da escola básica, Veeman (1988) usou a expressão "choque com a realidade", para expressar os conflitos existentes entre as idealizações feitas pelos professores e a realidade que eles encontram no espaço de trabalho quando iniciam a carreira. Para o autor, o choque com a realidade pode influenciar negativamente na postura dos professores recém-formados, pois tem efeitos que fazem com que os docentes percam a capacidade de inovação, elemento muito valorizado pelas escolas quando contratam profissionais iniciantes.

Huberman (1992), ao estudar o ciclo de vida dos professores, elucida que, ao iniciar o percurso profissional, o professor passa por uma fase de "sobrevivência" e "descoberta", permeada de confrontos entre o novo e a exploração de possibilidades de ação, avançando gradativamente para uma fase de "estabilização", em que começa a tomar maior consciência do papel e da responsabilidade que exerce como educador. Esse ciclo, conforme a definição do autor, não se constitui em etapas fixas, mas, sim, num processo dinâmico e bem peculiar ao percurso pessoal de cada professor.

Feixas (2002), investigando o contexto universitário, considera o início da carreira nesse nível de ensino um período difícil e que pode provocar insatisfações nos professores, levando-os a questionar a própria capacidade de atuar como docentes. A autora explica que, em muitos casos, o local de trabalho não é 
o que imaginaram e "muitos professores iniciantes se sentem pouco preparados para enfrentar os problemas e suportar a pressão institucional" (FEIXAS, 2002, p. 4). Em alguns casos, é possível observar que o fato de os docentes não se sentirem "preparados" pode ser uma das razões que os leva a desistir da profissão. Isso acontece quando as condições encontradas no contexto do trabalho são permeadas de experiências negativas e frustrantes com relação ao desenvolvimento da disciplina e também na convivência com os alunos.

Marcelo Garcia (2009) caracteriza os primeiros anos de docência como um período em que os profissionais precisam fazer a transição de alunos para professores, por isso é um momento carregado de muitas tensões e aprendizagens.

Para Isaia, Maciel e Bolzan (2010), os primeiros anos de docência constituem o período de converter-se em professor. No entanto, é preciso considerar que esse processo não é tarefa simples, pois exige saberes e conhecimentos que não foram aprendidos por todos na formação acadêmica. Geralmente os docentes universitários possuem um vasto conhecimento da área específica em que atuam, mas, como não tiveram formação para a docência, pouco ou nada conhecem sobre as questões ligadas ao ensino e, por isso, sentem-se, no início da carreira, geralmente angustiados, confusos com as decisões que devem tomar para que possam ensinar os alunos.

Sob esse aspecto, Papi e Martins (2010) mencionam que a fase de iniciação é um período que se inscreve como um tempo/ espaço privilegiado para a constituição da docência. De acordo com as autoras, 
os primeiros anos de exercício profissional são basilares para a configuração das ações profissionais futuras e para a própria permanência na profissão. Podem tornar-se um período mais fácil ou mais difícil, dependendo das condições encontradas pelos professores no local de trabalho, das relações mais ou menos favoráveis que estabelecem com outros colegas, bem como da formação que vivenciam e do apoio que recebem nessa etapa do desenvolvimento profissional (PAPI; MARTINS, 2010, p. 43).

A respeito, são importantes também as colocações de Marcelo Garcia (1999), quando explica que não devemos conceber o professor principiante como um "sujeito passivo, acrítico que assimila e imita as condutas e crenças da organização". Nessa perspectiva, os docentes iniciantes podem ser uma fonte de renovação das práticas de ensino desenvolvidas na universidade, especialmente se forem orientados e auxiliados para tal. Nesse contexto, passamos a abordar considerações sobre os programas de iniciação à docência, pois eles vêm sendo apontados como uma possibilidade de orientação e auxílio para professores iniciantes.

\section{PROGRAMAS DE INICIAÇÃO À DOCÊNCIA: ALGUMAS CONSIDERAÇÕES}

Os programas de iniciação à docência, também chamados de programas de indução ou inserção, de acordo com Ferreira e Reali (2005), são aqueles direcionados aos professores nas primeiras inserções profissionais e têm por propósito "auxiliar o ingresso na profissão de um modo menos traumático, tendo em vista o conjunto de demandas que recaem sobre 
os profissionais iniciantes e que exigem mudanças pessoais, conceituais e profissionais" (p. 2).

Na perspectiva de Marcelo Garcia (1999), os programas de iniciação para professores principiantes

\begin{abstract}
dão resposta à necessidade de ser facultada assessoria e formação aos docentes que se encontram no seu primeiro ano de ensino. Respondem [...] à concepção de que a formação de professores é um contínuo que tem de ser oferecida de um modo adaptado às necessidades de cada momento da carreira docente (MARCELO GARCIA, 1999, p. 119).
\end{abstract}

Bozu (2009) entende que o professor universitário necessita de uma etapa de socialização profissional baseada em formação específica, que o ajude a desempenhar melhor a função docente. Essa formação, na expectativa da autora, deve estar embasada na "capacitação didática, na aquisição de determinadas habilidades básicas, de caráter pessoal e também técnico, diretamente relacionadas à atividade docente" (p. 326). É nesse contexto que a existência de programas de iniciação assume papel fundamental: de acordo com Bozu (2009), esses programas podem amparar os professores no período inicial de enfrentamento da profissão e funcionar como um mecanismo prático de socialização.

De acordo com o estudo de Hiling-Austin (1986; 1990, apud MARCELO GARCIA, 1999), os objetivos que geralmente são buscados com a realização dos programas de iniciação à docência, além de estarem essencialmente voltados para melhorar a ação do profissional, também buscam "aumentar as possibilidades de permanência dos professores principiantes [...], promover o bem-estar pessoal e profissional dos 
professores principiantes e transmitir a cultura dos sistemas aos professores principiantes" (MARCELO GARCIA, 1999, p. 122).

Marcelo Garcia (2009) destaca que há grande variedade de características, conteúdos e componentes que podem ser observados nos programas de iniciação para os professores. O autor considera também que a duração e a intensidade são aspectos importantes, pois essas iniciativas podem variar "desde uma reunião simples de curso a um programa bem estruturado e que envolvem múltiplas atividades" (p. 21). Assim, a quantidade e a qualidade das experiências vivenciadas no momento em que os docentes se implicam nesses programas são elementos que denotam a sua relevância.

Recorrendo aos estudos desenvolvidos por Horn, Sterling y Subhan (2002), Marcelo Garcia (2009, p. 29) aponta os componentes que geralmente estruturam os programas de iniciação para docentes iniciantes a partir de estudos e pesquisas desenvolvidos em contextos internacionais, como destacado a seguir.

1. Orientação: atividade introdutória, desenvolvida antes de começar o curso, para que os professores iniciantes se situem no contexto do trabalho.

2. Mentor: é, quem sabe, o fator mais importante dos programas de inserção. Muito difundido devido ao baixo custo.

3. Ajuste das condições de trabalho: geralmente, reduz-se o número de alunos e as atividades extracurriculares do professor iniciante, proporcionam-se materiais, recursos e atividades de formação. 
4. Redução da carga horária: para permitir que os professores iniciantes possam realizar atividades de formação.

5. Desenvolvimento profissional: Realização de atividades de formação relacionadas com ensino, gestão da turma e da disciplina.

6. Colaboração entre colegas: é importante porque reduz a sensação de isolamento. Pode ser com grupos de professores que planejam e analisam.

7. Valorização do professor: periodicamente os docentes são observados para identificar seus pontos fortes e fracos. (MARCELO GARCIA, 2009, p. 29).

Esses componentes constituem-se como importante base para a organização de programas de iniciação e podem ajudar de modo peculiar no enfrentamento das necessidades específicas dos docentes em início de carreira.

Além desses componentes, é importante que os programas de inserção invistam em atividades formativas, enfatizando "experiências centradas na prática, nas necessidades dos alunos, na participação em projetos de inovação, no contato e na troca com outros professores iniciantes" (MARCELO GARCIA, 2009, p. 56). Essas atividades poderiam ajudar os docentes iniciantes a compreenderem a complexidade do ato de ensinar e a contribuírem para o desenvolvimento de práticas com mais qualidade e coerência.

De maneira geral, podemos considerar que os programas de inserção à docência, por meio das ações desenvolvidas no intuito de integrar, apoiar e orientar os docentes 
universitários iniciantes, olham atentamente para a fase peculiar que vivem esses profissionais, transformando esse período em um momento de reflexão, indagação, inovação e crescimento profissional docente. É um fato muito relevante para a reconstrução das práticas de ensino desenvolvidas na universidade e também para a consolidação do desenvolvimento profissional dos professores iniciantes.

As condições específicas dos professores iniciantes e a ocorrência de programas de iniciação/ indução/ inserção à docência nos estimularam a pesquisar se esses programas podem ser apontados como estratégias para ajudar os docentes em início de carreira. Buscamos, no contexto dessa investigação, saber como os professores iniciantes ${ }^{3}$ perceberam o Programa Formação/Integração do Professor Ingressante à Cultura Acadêmica da UFPel ${ }^{4}$, oferecido pela Universidade.

${ }^{3}$ Foram entrevistados 15 professores que trabalhavam no Centro de Desenvolvimento Tecnológico, no Centro das Engenharias, no Centro de Ciências Químicas, Farmacêuticas e de Alimentos e nas Faculdades de Veterinária e de Agronomia da Universidade Federal de Pelotas. Esses professores colaboraram com a pesquisa por meio de entrevistas semiestruturadas, baseadas nos preceitos de Bogdan e Biklen (1994) e realizadas pela autora da tese. A partir de um questionário previamente elaborado, buscamos investigar as principais percepções sobre o processo vivido durante a participação dos professores ingressantes do Programa de Formação/Integração do Professor Ingressante à Cultura Acadêmica da UFPel.

${ }^{4}$ O Programa Formação/Integração do Professor Ingressante à Cultura Acadêmica da UFPel foi desenvolvido pela universidade por meio da Pró-Reitoria de Graduação, durante dois anos, entre 2009 e 2011. Teve como objetivo geral subsidiar a avaliação institucional, a partir da integração do professor ingressante à cultura acadêmica da UFPel, e, como objetivos específicos: compartilhar os conhecimentos históricos constituídos na instituição; refletir sobre as atividades na UFPel como função e competência do professor; identificar caminhos que o próprio profissional pode vir a traçar no magistério superior; e pensar e viver o estágio probatório como momento de construção ou reconstrução 


\section{PROGRAMA DE FORMAÇÃO/INTEGRAÇÃO DO PROFESSOR INGRESSANTE À CULTURA ACADÊMICA DA UFPEL: PERCEPÇÕES DOS PROFESSORES UNIVERSITÁRIOS INICIANTES}

A partir das declarações feitas pelos entrevistados ${ }^{5}$ nesta pesquisa, foi possível inferir que, de maneira geral, iniciativas como a do Programa de Formação/Integração do Professor Ingressante à Cultura Acadêmica da UFPel se constituem, para os professores, em um lugar propício para refletir e discutir sobre aspectos fundamentais que permeiam a sala de aula. Ao serem indagados sobre a iniciativa da universidade de oferecer um programa dessa natureza, os docentes entrevistados deram respostas como:

Eu vejo que é um esforço da instituição para inserir o docente que chega aqui [...] é um esforço que a universidade está fazendo. (Professor J)

É uma ideia muito boa, uma ideia ótima, boa iniciativa, foi válido o programa. (Professor M)

\footnotetext{
profissional UFPel (2009). Teve caráter obrigatório para os docentes ingressantes na instituição e foi desenvolvido em torno de atividades como: palestras, seminários, minicursos e oficinas que versaram sobre: "O papel da UFPel no contexto do REUNI"; "Potencialidades do uso das tecnologias nos processos de ensino"; "Educação, ciência, e contemporaneidade: articulações, desafios, perspectivas"; "O lugar da experiência nos processos de professoralização"; "Desafios da profissão docente na atualidade"; "Educação do campo: origem, trajetória, atualidade e experiências da UFPel"; "Introdução de metodologias ativas: a experiência do programa de capacitação da UFCSPA"; "Metodologias do ensino superior: a aula universitária" e "Inclusão e acessibilidade no ensino superior".

${ }^{5}$ Como forma de preservar a identidade dos sujeitos, optamos por identificá-los por letras do alfabeto, e no decorrer do texto, tratamos todos por professores, não definindo assim o gênero.
} 
Também mencionaram que nesse programa tiveram a possibilidade de refletir sobre o fazer docente. Apesar de estarem no início da carreira, perceberam, por meio das discussões de que participaram durante as atividades, propostas que demonstravam que existem diferentes formas de ensinar e que é possível fazer práticas diferentes. Expressaram, ainda, que é produtivo conhecer práticas dos colegas, mesmo que esses atuem em áreas distintas. Disseram que:

O programa serviu para pensar e ver que alguma coisa diferente se pode fazer. Isso aí vai mais da autocrítica e, aí, tentar mudar. (Professor H)

(Conhecer) Outras experiências de cursos, por exemplo, eu lembro uma que foi muito bacana, o pessoal do curso de Nutrição, bem distante da nossa área, de Computação, mas eles relatando lá as experiências que eles tinham ao longo da construção do currículo deles. (Professor I)

A partir dos depoimentos acima, podemos observar que 0 programa se constituiu em um espaço para esses professores perceberem que há possibilidades diversas de pensar e de desenvolver a docência.

Ao ouvirem as experiências relatadas pelos colegas, puderam se aproximar de exemplos práticos transcorridos por seus pares e refletir sobre as próprias práticas. Essa possibilidade se configurou como uma forma de aprender a docência, já que, como indica Marcelo Garcia (2009, p. 11), "para aprender, os professores necessitam utilizar de exemplos práticos, materiais como casos escritos, casos multimídia, observações de ensino, diários de professores e exemplos de tarefas de alunos". 
A docência é uma atividade dinâmica e exige do professor uma reconstrução profissional constante, pois os contextos em que ela ocorre também se modificam, exigindo continuamente novas configurações práticas. Entretanto, nem sempre o professor tem espaços e tempos para refletir sobre a reconfiguração de suas práticas, por vezes, também, tem dificuldades de encontrar parceiros para socializar experiências e para estudar junto com ele novas formas de ensinar e aprender.

A problematização e a discussão sobre as experiências iniciais também foram citadas como aspectos importantes nas atividades propostas no programa, em especial na modalidade de minicursos.

Os respondentes entenderam que essa atividade do programa foi muito importante e que possibilitou trocar impressões e dificuldades. Consideraram que foi um espaço para ouvir e ser ouvido e também para observar como os colegas resolvem dificuldades em início de carreira. Relatos como os que se seguem indicam a relevância desta atividade.

Outro curso, agora no final, que era de metodologia de ensino, as discussões nesse curso foram bem válidas [...] Acho que porque é um grupo restrito de pessoas, limitado [...] ali nesse minicurso tu senta, tem a possibilidade de discutir de falar das experiências, das maneiras que uma pessoa faz, aí, tu pensa: "isso é bom". (Professor G)

A possibilidade de discutir coletivamente as experiências vividas no período inicial da docência foi destacada pelos entrevistados. No contexto dos minicursos, encontraram espaço para relatar as dificuldades, os desafios e também para 
observar a forma como cada um de seus colegas vai tentando trabalhar sobre essas questões cotidianamente.

Em estudos realizados por Anastasiou (2011), a autora observou que, quando os professores universitários têm a oportunidade de compartilhar ações, soluções, possibilidades de integração entre as disciplinas, assim como incertezas, questionamentos e fracassos, eles aumentam a vontade de acertar, de trabalhar colegiadamente. Além disso, percebem que o compromisso com a graduação vai além de situações pensadas de forma isolada, abrange um conjunto de ações necessárias para o bem dos alunos e dos cursos.

Sobre reflexão em grupo, Ibipiana e Ferreira (2002) consideram que

\begin{abstract}
as reflexões realizadas nos grupos possibilitam a construção do conhecimento mais sólido acerca da prática, o que potencialmente implica no desencadeamento de um processo de autoavaliação sobre os aspectos que necessitam ser aprimorados no percurso do desenvolvimento profissional. Privilegiando a construção de novas relações de trabalho e possibilitando o enfrentamento coletivo das condições objetivas e subjetivas do seu trabalho (IBIPIANA; FERREIRA, 2002, p. 895).
\end{abstract}

As autoras enfatizam que o processo de reflexão incentiva o professor ao crescimento profissional, tanto no nível individual quanto no coletivo, fazendo com que ampliem gradativamente a consciência sobre a função que exercem, dando a ela sentido e significado, alterando as condições objetivas de trabalho. Além disso, a discussão realizada com os colegas de profissão sobre o desenvolvimento das atividades, embora não seja 
garantia de transformações de práticas, é indispensável para desencadear processos de mudança, pois, no grupo, ocorrem avaliações individuais e coletivas, e, assim, os participantes podem superar práticas consolidadas, por meio do exercício de reflexibilidade. Ao explicarem por que agem desta ou daquela forma, os professores relacionam o como fazem com o que pensam, revelando, dessa forma, os conceitos que guiam a própria prática (IBIPIANA; FERREIRA, 2002).

O acesso a materiais de leitura com fundamentações teóricas sobre os conhecimentos pedagógicos e as provocações a respeito das relações entre professor e aluno, realizados no programa, foram destacados pelos respondentes como possibilidades de eles entenderem melhor o ensino que desenvolvem. Disseram os entrevistados que:

O material que a gente lia era um material bem bom. Toda aquela questão de eu ir dar a aula, ou trocar experiências, ou ir construir, toda aquela história junto, tinha também os métodos. (Professor L)

A parte pedagógica, do conceito do aluno dentro da sala de aula do professor; conceitos como construção e desconstrução. (Professor F)

Essas considerações são importantes se atentarmos para o fato de que os professores entrevistados estão construindo sua forma de ser professor, estão aprendendo a sê-lo no enfrentamento das situações cotidianas da docência. O apreço que demonstraram pelas atividades do programa que discutem o ensino e que lhes dão ferramentas teóricas para problematizar o exercício da docência se deve ao fato de que, durante os estudos no mestrado e no doutorado, não tiveram oportunidades de discutir o tema. 
Desse modo, o programa, para esses professores, ajudou a pensar o ensino como uma atividade que

\begin{abstract}
requer conhecimentos específicos, consolidados por meio de formação voltada especialmente para esse fim, bem como de atualização constante das abordagens dos conteúdos e das novas maneiras didáticas de ensiná-los. A mediação da prática coloca-se como indispensável, porém, em estreita articulação com a teoria e ancorada na reflexão, enquanto processo que busca sentido àquilo que se pratica (PIMENTA; ALMEIDA, 2011, p. 27).
\end{abstract}

Expressões como "construir junto com o aluno" (professor L) e "diferença cultural do aluno [...] Construção e desconstrução" (professor F) indicam que, por meio das atividades de que participaram, os docentes puderam refletir sobre aspectos importantes a respeito da relação professor/aluno/ conhecimento.

A possibilidade de problematizar esses aspectos se configura como oportunidade significativa para que o professor possa, desde o início da carreira, ir superando a compreensão do espaço da sala de aula como espaço apenas de transmissão do saber e se perceba como mediador da aprendizagem dos alunos, um profissional capaz de fazer a intermediação entre o conhecimento e o estudante, mobilizado a investir em uma aprendizagem significativa, com base na problematização da realidade.

É importante considerar que os respondentes reconheceram que há ainda um longo caminho a ser trilhado no intuito de se adequar às atividades, melhorar as propostas, mas é importante reconhecer que algo foi realizado em prol da formação desses 
professores. A respeito, os entrevistados sugerem que sejam oferecidas possibilidades de aperfeiçoamento, readequações, redimensionamentos das ações desenvolvidas no programa. Destacaram que as temáticas utilizadas, os modos de conduzir as atividades, o número de participantes, a organização e a pontualidade no desenvolvimento das atividades, o estímulo e as condições de participações nas atividades, o número de vagas nas atividades, as atividades que enfatizam a formação pedagógica, a diversificação das atividades, a continuidade de formação e a interação entre os responsáveis e entre as atividades são questões que precisam ser revistas dentro da proposta das atividades do programa. Talvez uma forma de repensar os focos das atividades do programa seja a partir da análise das expectativas dos professores iniciantes em relação a ele.

Os interlocutores expressaram que, para que um programa seja desenvolvido com e para docentes ingressantes, deve-se primeiramente: ouvir os professores para poder identificar as necessidades deles; acompanhar esse professor, dotando-o de capacidade de análises sobre as próprias práticas e auxiliandoos para que possam melhorar continuamente. Nas palavras dos docentes:

\footnotetext{
Eu vejo que deveria conversar com o professor, identificar com o professor, não fazer algo de qualquer jeito [...] eu acho que se deveria consultar o professor, no sentido de "olha, o que a gente pode fazer pra melhorar a questão do ensino?", partindo deles um direcionamento, porque, senão, fica muito amplo, a palestra, cada um tem seu direcionamento diferente e acaba não rendendo, eu vejo que se eles fossem até o professor, eu vejo que seria melhor. (Professor K)
} 
Acompanhamento do professor aqui dentro [...] alguém que acompanhasse mais aqui dentro, como é que está a tua sala? O que tu estás precisando? Alguém que estivesse responsável [...] "deixa o professor tal junto contigo aqui". (Professor B)

A partir das respostas dos interlocutores, é possível perceber que, nos momentos em que são propostos espaços de formação, é preciso, como primeiro passo para a efetivação deles, investigar com os professores o que mais os inquieta, quais são dificuldades e necessidades. Para Murillo et al. (2006, p. 4), as necessidades são entendidas como carências de algo inevitável ou desejável. A análise das necessidades é uma forma de "coletar e analisar as informações para identificar as carências de indivíduos, grupos ou instituições que precisam mudar e melhorar".

Esse levantamento anterior ao desenvolvimento das atividades do programa ajuda na organização e na concretização dos objetivos, pois, como aponta Tavares (1997), previamente aos processos de formação, precisamos entender como as pessoas envolvidas no processo pensam, agem, se comportam e que problemas elas têm. Trata-se de, a partir do contexto observado, construir um diagnóstico sobre as necessidades formativas dos professores iniciantes.

Esse diagnóstico serve como ponto de partida para a discussão coletiva da proposta a ser desenvolvida e já se constitui também como ação formativa, pois permite que o professor reflita sobre as próprias práticas no intuito de selecionar os aspectos centrais a serem trabalhados. É com base nesse diagnóstico que devem ser construídas as estratégias para a formação e a inserção dos professores. Desse modo, as temáticas poderiam 
ser mais bem trabalhadas e também se aproximar mais ao que de fato é pertinente para o aperfeiçoamento de professores universitários iniciantes e, assim, talvez pudessem fazer mais sentido ao contexto do trabalho desses docentes.

Se nos remetermos aos desafios enfrentados pelos sujeitos, veremos que eles perpassam com muita ênfase aspectos que envolvem a sala de aula, ou seja: o relacionamento com os alunos; o planejamento das aulas e das avaliações; a seleção de conteúdos; a forma de tornar esse conteúdo atrativo para o aluno; as estratégias para manter a atenção dos alunos e para trabalhar a partir do nível de conhecimento de cada um deles. Por isso, os temas que os professores universitários mais precisam discutir e se aprofundar devem estar relacionados com "o planejamento, a metodologia, os diferentes sistemas de avaliação, o trabalho com alunos em uma universidade para todos e que todos podem acessar, a construção dos conhecimentos, a participação nas tarefas e a tomada de decisões" (MURILLO et al., 2006, p. 3).

Entendemos que a formação de todo professor é um processo e, portanto, é preciso apostar efetivamente na continuidade dessa formação, abrir espaços para a reflexão, garantir acompanhamento do processo e, principalmente, propor o desenvolvimento de atividades que garantam o tratamento adequado das temáticas que envolvem a docência na universidade. É preciso fazer a interlocução dos conhecimentos específicos que o professor domina e ir avançando, mostrando a necessária articulação entre as componentes pessoais, científicas e pedagógicas. 


\section{ALGUMAS CONCLUSÕES}

A partir dos achados, podemos inferir que o programa desenvolvido pela universidade se constituiu em uma iniciativa importante de formação e inserção dos professores universitários entrevistados. Contudo, foi possível observar que, quando forem organizadas atividades dessa natureza, primeiramente, deve-se ouvir os professores, para que se possa conhecer e atender melhor as necessidades de formação. Além disso, é necessário manter o acompanhamento do docente iniciante, para que ele consiga cultivar práticas educativas constantemente revisadas e aprofundadas ao longo da trajetória em sala de aula. Acreditamos que, assim, esses programas poderiam, sim, se constituir como possibilidades de formação e desenvolvimento profissional para professores iniciantes e, dessa forma, estes poderiam construir práticas mais condizentes com o contexto universitário atual, além de que poderiam se sentir mais amparados nessa fase da carreira e em condições de fazer frente aos desafios existentes no cotidiano de professor universitário.

\section{REFERÊNCIAS}

ANASTASIOU, Lea das Graças Camargos. Processos formativos de docentes universitários: aspectos teóricos e práticos. In: PIMENTA, Selma Garrido; ALMEIDA, Maria Isabel de. Pedagogia Universitária: caminhos para a formação de professores. São Paulo: Cortez, 2011. p. 4474.

BOZU, Zoia. El profesorado universitario novel y su proceso de inducción profesional. Magis, Revista Internacional de 
Investigación en Educación. v. 1, n. 2. p. 317-328. Bogotá, Colombia, enero-junio 2009.

BOZU, Zoia. Los jóvenes profesores universitarios en el contexto actual de la enseñanza universitaria. Claves y controversias. Revista Iberoamericana de Educación, n. 51/3, p. 1-15. Enero 2010.

BRASIL. Lei de Diretrizes e Bases da Educação Nacional (LDB). Lei no 9.394, de 20 de dezembro de 1996. Estabelece as diretrizes e bases da educação nacional. Disponível em: <http://portal.mec.gov.br/arquivos/pdf/ Idb.pdf>. Acesso em: 10 de abr. 2013.

FEIXAS, Mónica. El profesorado novel: Estudio de su problemática en la Universitat Autónoma de Barcelona. Revista de Docencia Universitaria, v. 2, n. 1, p. 1-17. Universidade de Murcia, 2002.

FERREIRA, Lílian Aparecida; REALI, Aline Maria de Medeiros Rodrigues. Aprendendo a ensinar e a ser professor: Contribuições e desafios de um programa de iniciação à docência para professores de Educação Física. In: Anais da 28 Reunião Anual da Anped, Caxambu, 2005. p. 1-17. Disponível em: <http://www.anped.org. br/reunioes/28/inicio.htm>. Acesso em: 15 de jun. 2011.

HUBERMAN, Michaël. O ciclo de vida profissional dos professores. In: NÓVOA, António. Vidas de Professores. Portugal: Porto Editora, LDA, 1992. p. 31-51.

IBIPIANA, Ivani Maria; FERREIRA, Salonilde. O professor universitário: um percurso singular de profissionalização. In: Anais XIII Colóquio da AFIRSE/AIPELF. A formação de professores à luz da investigação. Universidade de Lisboa, Lisboa, 2002. p. 889-897. 
ISAIA, Silvia Maria de Aguiar; MACIEL, Adriana Moreira da Rocha; BOLZAN, Doris Pires Vargas. Educação superior: a entrada na docência universitária. In: Anais da 33^ Reunião Anual da Anped, Caxambu, 2010. p. 1-16. Disponível em: <http://www.anped.org.br/33encontro/ internas/ver/trabalhos-gt08>. Acesso em: 18 jun. 2011.

MARCELO GARCIA, Carlos. Formação de professores: para uma mudança educativa. Porto: Porto Editora, 1999.

MARCELO GARCIA, Carlos. El profesorado principiante: inserción a la docencia. Barcelona: Octaedro, 2009.

MAYOR RUIZ, Cristina. El desafio de los profesores principiantes universitarios ante su formación. In: MARCELO GARCIA, Carlos. El profesorado principiante: inserción a la docencia. Barcelona: Octaedro, 2009. p. 177-210.

MURILLO, Paulino et al. Las necesidades formativas docentes de los profesores universitarios. In: Revista Fuentes, v. 6, p. 1-22. Universidade de Sevilha, 2005.

PAPI, Silmara de Oliveira; MARTINS, Pura Lúcia. As pesquisas sobre professores iniciantes: algumas aproximações. In: Educação em Revista, Belo Horizonte, v. 26, n. 3, p. 39-56, dez. 2010.

PIMENTA, Selma Garrido; ALMEIDA, Maria Isabel de (Orgs.). Pedagogia Universitária. São Paulo: Editora da Universidade de São Paulo, 2009.

TAVARES, José. A formação como construção do conhecimento científico e pedagógico. In: SÁ-CHAVES, Idália (Org.). Percursos de formação e desenvolvimento profissional. Portugal: Porto Editora, 1997. p. 59-74. 
VEENMAN, Simon. El proceso de llegar a ser profesor: un análisis de la formación inicial. In: VILLA, Aurelio (Coord.). Problemas y perspectivas de la formación docente. Madrid: Narcea, 1988. p. 39-68.

\begin{abstract}
This study aimed at investigating beginning professors' perception regarding their teacher education program and their integration into teaching processes in a university in Rio Grande do Sul, a state located in the south of Brazil. This qualitative research was carried out with 15 professors who had been teaching from 0 to 5 years. Data were collected by interviews and analyzed in the light of significant studies, such as Marcelo Garcia's (1999, 2009) and Mayor Ruiz's (2007, 2009). It may be stated that this type of programs has become an actual option in teacher education and has qualified professional development processes when they enable pedagogical discussions and help professors to be integrated into the university environment.
\end{abstract}

Keywords: Beginning Professors. Teacher Education. Professional integration programs.

\title{
Neridiana Fabia Stivanin
}

Possui graduação em Pedagogia, especialização em Gestão Educacional e mestrado em Educação pela UFSM. Cursou doutorado em Educação na Universidade Federal de Pelotas, 
realizando, no período, estágio doutoral no Instituto de Educação da Universidade de Lisboa/Portugal. Participa do grupo de pesquisa Pedagogia Universitária - Formação de Professores na UFPel. Temas de interesse: formação de professores e pedagogia universitária.

nstivanin@yahoo.com.br

\section{Beatriz Maria Boéssio Atrib Zanchet}

Possui licenciatura plena em Matemática pela UCPel, especialização em Matemática pela UFPel, mestrado em Educação pela UFSM, doutorado em Educação pela Universidade do Vale do Rio dos Sinos e pós-doutorado pela mesma instituição. Atualmente é professora titular da Universidade Federal de Pelotas. Tem experiência na área de Educação, com ênfase em ação docente.

biazanchet@gmail.com 